\title{
Hidrólise da cana-de-açúcar com cal virgem ou cal hidratada
}

\author{
Diego Azevedo Mota ${ }^{1}$, Mauro Dal Secco de Oliveira ${ }^{1}$, Felipe Nogueira Domingues ${ }^{1}$, Gabriela \\ Milani Manzi ${ }^{1}$, Daniel de Souza Ferreira ${ }^{2}$, Juliana dos Santos ${ }^{1}$
}

\footnotetext{
${ }^{1}$ UNESP - Faculdade de Ciências Agrárias e Veterinárias - Departamento de Zootecnia - Campus de Jaboticabal.

2 Colégio Técnico Agrícola "José Bonifácio".
}

RESUMO - Objetivou-se estudar o efeito do tratamento alcalino da cana-de-açúcar com cal virgem ou cal hidratada sobre a composição bromatológica e a digestibilidade in vitro da matéria seca, da fibra em detergente neutro e da fibra em detergente ácido. Utilizou-se um delineamento inteiramente casualizado em esquema fatorial $3 \times 3$, composto de três formas de processamento da cana (in natura; cana hidrolisada com $0,5 \%$ de cal virgem; e cana hidrolisada com $0,5 \%$ de cal hidratada) e três tempos de armazenamento (12, 36 e 60 horas). As formas de processamento influenciaram os teores de matéria orgânica, matéria mineral, carboidratos totais e hemicelulose, assim como os teores de fibra em detergente neutro e nutrientes digestíveis totais. Os tempos de armazenamento influenciaram os teores de proteína bruta, matéria orgânica, carboidratos totais e hemicelulose. Entre os minerais, somente o teor de cálcio teve aumento com a inclusão de ambos os tipos de cal em relação à cana-de-açúcar, que não sofreu o processo de hidrólise. Os coeficientes de digestibilidade da matéria seca e da fibra em detergente neutro aumentaram com a hidrólise da cana em comparação à cana in natura. A hidrólise com cal hidratada ou com cal virgem mantém o valor nutricional da cana-de-açúcar, permitindo que possa ser utilizada depois de até 60 horas de armazenamento.

Palavras-chave: cal hidratada, cal virgem, Saccharum officinarum L., tratamento químico, valor nutritivo

\section{Hydrolysis of cane sugar with lime or hydrated lime}

\begin{abstract}
The objective of the present work was to evaluate the effect of the alkaline treatment of sugarcane with virgin lime or hydrated lime on the bromatologic composition and in vitro digestibility of dry matter, neutral detergent fiber, and acid detergent fiber. It was used a complete random design with a $3 \times 3$ factorial scheme composed by three forms of of sugarcane processing (in natura sugarcane; hydrolyzed sugarcane with $0.5 \%$ virgin lime; and hydrolyzed sugarcane with $0.5 \%$ hydrated lime) and three storage times (12, 36 and 60 hours). The forms of processing changed the contents of organic matter, mineral matter, total carbohydrates, and hemicellulose as well as the contents of neutral detergent fiber and total digestible nutrients. Times of storage changed contents of crude protein, organic matter, total carbohydrates and hemicellulose. Among the minerals, only content of calcium showed an increase for the sugarcane processing forms. Coeficients of digestibility of dry matter and neutral detergent fiber increased with hydrolises of sugar cane when compared to in natura sugarcane. Hydrolisis with hydrated lime or with virgin lime keeps the nutrional value of sugarcane making its use possible up to 60 hours after storage.
\end{abstract}

Key Words: chemical treatment, hydrated lime, nutritional value, Saccharum officinarum L., virgin lime

\section{Introdução}

A cana-de-açúcar destaca-se como volumoso para alimentação de bovinos no período da seca pela produção elevada e por apresentar o menor custo da tonelada de matéria seca (MS) e energia. Entretanto, apresenta baixo teor de compostos nitrogenados e de minerais, assim como reduzida digestibilidade da fibra, que causa diminuição no consumo de MS emenor ingestão de nutrientes (Oliveira, 1999).
Tradicionalmente, o uso de cana-de-açúcar baseiase no corte diário e no fornecimento imediato da forragem fresca. Recentemente têm sido divulgada a utilização de cal virgem $(\mathrm{CaO})$ e cal hidratada $\left[\mathrm{Ca}(\mathrm{OH})_{2}\right]$ no tratamento da cana-de-açúcar com o intuito de manter qualidades nutritivas desta forrageira por alguns dias sem a necessidade de cortes diários (Oliveira et al., 2007).

A utilização desta técnica trás aos produtores melhor qualidade de vida, já que diminui a frequência de corte 
da forragem e o emprego de mão-de-obra sem a necessidade de investimento em equipamentos.

Apesar dos benefícios, ainda são poucos os trabalhos sobre o assunto na literatura e geralmente os resultados são obtidos com apenas um tipo de cal. Assim torna-se oportuna a realização de experimentos científicos para comparação da cal virgem e da cal hidratada.

Assim, objetivou-se avaliar a composição bromatológica e o desdobramento da composição da matéria mineral e estimar a digestibilidade in vitro da matéria seca, da fibra em detergente neutro (FDN) e da fibra em detergente ácido (FDA) da cana-de-açúcar in natura hidrolisada com cal virgem ou cal hidratada durante 12, 36 e 60 horas de armazenamento.

\section{Material e Métodos}

O experimento foi conduzido na FCAV/UNESP, Campus de Jaboticabal/SP, em agosto de 2006, no Setor de Bovinocultura de leite. A cana-de-açúcar utilizada foi o cultivar IAC 86-2480, com corte realizado em soqueira aos 12 meses ( $2^{\circ}$ corte).

De acordo com os níveis de garantia do fabricante, a cal virgem apresentava mínimo de 90,00\% de óxido de cálcio total (CaO) e máximo de 0,50\% de óxido de magnésio total, enquanto a cal hidratada, mínimo de 95,00\% de hidróxido de cálcio e máximo de 1,50\% de óxido de magnésio total.

Foram estabelecidos os seguintes fatores de estudo: três formas de processamento = cana in natura; cana hidrolisada com $0,5 \%$ de cal virgem $(\mathrm{CaO})$, e cana hidrolisada com $0,5 \%$ de cal hidratada $\left(\mathrm{Ca}(\mathrm{OH})_{2}\right) \times$ três tempos de armazenamento (12, 36 e 60 horas).

A cana foi picada em picadeira estacionária, proporcionando tamanhos de partícula de aproximadamente $8 \mathrm{~mm}$. Preparou-se a mistura da cal hidratada e cal virgem com água para os amontoados de 15 kg de cana-de-açúcar, mantendo-se as proporções de 0,5 kg de cal: 2 litros de água: $100 \mathrm{~kg}$ de cana, respectivamente. Em seguida as soluções foram esparramadas sobre os amontoados de cana correspondentes, e cuidadosamente o material foi homogeneizado. Posteriormente, os amontoados foram submetidos a 12; 36 e 60 horas de armazenamento. Ao final de cada tempo, foram retiradas amostras, que foram acondicionadas a $-5^{\circ} \mathrm{C}$ para posteriores análises.

Na determinação da composição bromatológica, foram determinados os teores de: matéria seca (MS), matéria mineral (MM) e proteína bruta (PB) de acordo com as metodologias descritas por Silva \& Queiroz (2002). Os teores de fibra em detergente neutro (FDN) e fibra em detergente ácido (FDA) foram avaliados pelo método sequencial descrito por Robertson \& Van Soest (1981). Para determinação da lignina foi utilizado o ácido sulfúrico a 72\% (Van Soest, 1994), enquanto os teores de hemicelulose, celulose e matéria orgânica foram calculados pelas diferença entre FDN, FDA, entre FDA e lignina e entre MS e matéria mineral, respectivamente.

Foram determinados os teores de cálcio, fósforo, potássio, magnésio e ferro de todos os tratamentos, conforme metodologia descrita por Silva \& Queiroz (2002).

No ensaio de digestibilidade in vitro utilizou-se um novilho macho SRD com $300 \mathrm{~kg}$ de peso vivo como doador de conteúdo ruminal, o qual permaneceu numa baia contendo cocho de alimentação e bebedouro, onde recebeu $25 \mathrm{~kg}$ de cana-de-açúcar, valor dividido igualmente em cana fresca (picada diariamente), cana hidrolisada com $0,5 \%$ de cal virgem e cana hidrolisada com $0,5 \%$ de cal hidratada $+3 \mathrm{~kg}$ de concentrado (mistura de milho + farelo de soja + mistura mineral) durante 15 dias para a adaptação. A primeira coleta do conteúdo ruminal foi feita pela manhã do $16^{\circ}$ dia do início da adaptação. O material foi colhido manualmente antes da primeira refeição e as demais coletas foram realizadas sempre às terças-feiras de cada semana, até o final de todas as rodadas estabelecidas.

A quantidade de rodadas (quatro) e o número de repetições por amostra (dez) foram estabelecidos para obtenção de resíduo suficiente para a determinação dos teores de matéria seca (MS), de fibra em detergente neutro (FDN) e de fibra em detergente acido (FDA).

Rapidamente, foi feita a filtragem do conteúdo ruminal em tecido de algodão, por meio de pressão manual, para obtenção do líquido ruminal, o qual foi acondicionado adequadamente em uma garrafa térmica contendo água previamente aquecida a $39^{\circ} \mathrm{C}$ a fim de manter a temperatura e, após a retirada da quantidade necessária, injetou-se ao mesmo gás $\mathrm{CO}_{2}$ a fim de manter a anaerobiose.

O líquido obtido foi utilizado para inoculação nos jarros de fermentação do fermentador ruminal DAISY II, contendo os sacos de fermentação com as amostras e a saliva artificial. Quantidades de 0,5 g de cada amostra foram colocadas em sacos de fermentação e estes no fermentador ruminal DAISY II, durante 48 horas e posteriormente com pepsina e ácido clorídrico durante 24 horas.

Foram determinados os coeficientes de digestibilidade in vitro da matéria seca (DIVMS), da fibra em detergente neutro (DIVFDN) e da fibra em detergente ácido (DIVFDA), obtidos segundo a técnica descrita por Holden (1999).

Foi utilizado o delineamento inteiramente casualizado em esquema fatorial $3 \times 3$, composto de três formas de processamento e três tempos de armazenamento, cada um 
com três repetições. Compararam-se as médias dos tratamentos pelo teste Tukey, utilizando-se o pacote estatístico SAS.

\section{Resultados e Discussão}

Não houve efeito $(\mathrm{P}>0,05)$ das formas de processamento nem dos tempos de armazenamento sobre o teor de matéria seca (MS). No entanto houve diferença $(\mathrm{P}<0,01)$ nos valores de matéria orgânica (MO) entre as formas de processamento. Valores menores foram observados para as formas de processamento e para hidrólise com ambas as cales (Tabela 1). Esse resultado já era esperado, visto que a inclusão de cal causou aumento nos teores de matéria mineral e diminuição nos valores de matéria orgânica. Os tempos de armazenamento não influenciaram $(\mathrm{P}>0,05)$ o teor de matéria orgânica.

Os teores de matéria mineral diferiram somente entre as formas de processamento $(\mathrm{P}<0,01)$, de modo que, como previsto, a cana in natura apresentou o menor valor (2,04\%) para essa variável. A cana hidrolisada com $0,5 \%$ de cal virgem e cal hidratada apresentou respectivamente médias de 4,09 e 3,32\%. Os tempos de armazenamento não influíram no teor de matéria mineral $(\mathrm{P}>0,05)$. Oliveira et al. (2008a) também encontraram redução e aumento nos teores de matéria orgânica e matéria mineral, respectivamente, relacinadas à cal hidratada.

O teor de PB somente sofreu influência dos tempos de armazenamento $(\mathrm{P}<0,01)$. Domingues et al. (2007) também notaram aumento no teor de PB no decorrer do tempo de armazenamento. Segundo esses autores este aumento se deve à presença de microrganismos, leveduras e fungos, que são analisados juntamente com a cana.

Houve redução $(\mathrm{P}<0,01)$ nos teores de fibra em detergente neutro (FDN) e hemicelulose da cana hidrolisada em comparação à cana in natura. A redução nessas frações resultou da solubilização parcial dos constituintes da parede celular, pois o efeito dos produtos alcalinos normalmente ocorre pela solubilização parcial da hemicelulose e pela expansão da celulose, o que facilita o ataque dos microrganismos do rúmen à parede celular (Jackson, 1977). Consequentemente, a parte solubilizada foi perdida durante o processo de filtração para a retirada do detergente neutro (Domingues et al. 2007). Também houve aumento $(P<0,01)$ nos teores de FDN e de hemicelulose da cana com o aumento nos tempos de armazenamento. Este aumento foi percentual e ocorreu devido à maior intensidade e, em menor tempo, da atividade de leveduras e fungos filamentosos (Amaral, et al, 2009) que possivelmente consumiram os carboidratos solúveis presentes na cana-de-açúcar.

O efeito alcalinizante da cal provoca a solubilização parcial da hemicelulose, a qual foi evidenciada neste trabalho. Também ocorre o intumescimento alcalino da celulose, que consiste na expansão das moléculas de celulose, causando ruptura das ligações das pontes de hidrogênio (Jackson, 1977). Nas condições deste trabalho, o intumescimento alcalino da celulose não ocorreu, por isso não houve efeito nem das formas de processamento e nem dos tempos de armazenamento $(\mathrm{P}>0,05)$, nessa variável.

Semelhante à celulose, o teor de lignina não foi alterado (P>0,05). De acordo com Klopfenstein (1980), o teor de lignina normalmente não é alterado pelo tratamento químico.

Tabela 1 - Composição bromatológica e desdobramento da fração mineral da cana-de-açúcar hidrolisada com cal virgem ou cal hidratada

\begin{tabular}{|c|c|c|c|c|c|c|}
\hline \multirow[t]{2}{*}{ Item } & \multicolumn{3}{|c|}{ Forma de processamento } & \multicolumn{3}{|c|}{ Tempo de armazenamento } \\
\hline & In natura & $\begin{array}{c}\text { Hidrólise } \\
\text { com cal } \\
\text { virgem }\end{array}$ & $\begin{array}{l}\text { Hidrólise } \\
\text { com cal } \\
\text { hidratada }\end{array}$ & 12 horas & 36 horas & 60 horas \\
\hline Matéria seca (\%) & 24,76 & 25,00 & 25,03 & 25,12 & 24,70 & 24,97 \\
\hline Matéria orgânica (\%) & $96,94 a$ & $94,29 c$ & $95,29 b$ & 95,99 & 95,21 & 95,18 \\
\hline Matéria mineral (\%) & $2,04 \mathrm{c}$ & 4,09a & $3,32 b$ & 2,95 & 3,20 & 3,30 \\
\hline Proteína bruta (\%) & 2,65 & 2,51 & 2,53 & $2,18 b$ & $2,75 a$ & $2,75 a$ \\
\hline Fibra detergente neutro (\%) & $45,25 a$ & $41,10 \mathrm{~b}$ & $40,07 b$ & 39,68 & 43,08 & 43,67 \\
\hline Fibra detergente acido (\%) & 19,66 & 18,44 & 18,71 & 17,60 & 20,20 & 19,00 \\
\hline Hemicelulose (\%) & $25,59 a$ & $22,66 b$ & $21,36 b$ & $22,06 b$ & $22,87 b$ & $24,67 a$ \\
\hline Celulose (\%) & 15,20 & 13,96 & 14,15 & 13,11 & 15,77 & 14,42 \\
\hline Lignina (\%) & 4,46 & 4,48 & 4,54 & 4,50 & 4,43 & 4,57 \\
\hline Cálcio (\%) & $0,17 \mathrm{c}$ & $1,03 a$ & $0,77 b$ & 0,70 & 0,57 & 0,69 \\
\hline Fósforo (\%) & 0,07 & 0,07 & 0,06 & 0,06 & 0,07 & 0,07 \\
\hline Magnésio (\%) & 0,97 & 0,96 & 0,94 & 0,95 & 0,95 & 0,97 \\
\hline Potássio (\%) & 0,59 & 0,61 & 0,55 & 0,59 & 0,58 & 0,58 \\
\hline Ferro (mg/kg) & 247,55 & 254,44 & 257,66 & 257,77 & 249,88 & 257,00 \\
\hline
\end{tabular}

Médias seguidas de mesma letra na coluna não diferem entre si pelo teste Tukey. 
Os resultados estatísticos comprovam efeito das formas de processamento $(\mathrm{P}<0,01)$ somente sobre as porcentagens de cálcio. Em média, o aumento de cálcio foi de 605,88 e $452,94 \%$, respectivamente, para a cana hidrolisada com cal virgem e cal hidratada em relação à cana in natura.

A proporção de minerais essenciais nas cinzas da cana-de-açúcar é extremamente baixa (Oliveira 1999). Entretanto, ao optar pela utilização da cana hidrolisada com cal, deve-se atentar não só para a formulação da ração, a fim de proporcionar uma dieta equilibrada em minerais, especialmente cálcio e fósforo, mas também considerar a biodisponibilidade desses minerais, visto que esses valores podem sofrer alterações, conforme a cal utilizada.

As concentrações dos demais minerais estudados (fósforo, magnésio, potássio e ferro) não foram influenciadas pelo tipo de processamento da cana-de-açúcar $(\mathrm{P}>0,05)$. Os teores desses minerais, exceto de magnésio, encontrados neste trabalho estão dentro dos valores normais encontrados na cana-de-açúcar, os quais foram apresentados por Boin et al. (1987).

O tempo de armazenamento não teve efeito significativo $(\mathrm{P}>0,05)$ sobre as concentrações de nenhum dos minerais estudados.

Houve efeito $(\mathrm{P}<0,01)$ das formas de processamento para a digestibilidade da matéria seca e de fibra em detergente neutro (Tabela 2). $\mathrm{O}$ aumento da digestibilidade ocorre de acordo com a ação alcalinizante da cal, em virtude da solubilização da fração fibrosa da cana-deaçúcar. Moraes et al. (2008) não encontraram diferenças sobre a digestibilidade aparente total de FDN, que não foi influenciada pela adição de cal virgem à cana-de-açúcar. Embora os valores absolutos da digestibilidade in vitro e in vivo não devam ser comparados, os resultados relativos podem servir como parâmetro de comparação do comportamento da variável. Oliveira et al. (2008b) também não encontraram influência da hidrólise com a cal hidratada na digestibilidade in vitro da fibra em detergente neutro, nem nos níveis (0, 0,5 e 0,6\%) e nem nos tempos (3, 6 e 9 horas) analisados e alegaram que a quantidade aplicada não foi suficiente para causar o efeito hidrolisante significativo sobre a cana-de-açúcar.

O tempo de armazenamento não influenciou $(\mathrm{P}>0,05)$ a digestibilidade da matéria seca nem da fibra em detergente neutro. O coeficiente de digestibilidade da fibra em detergente ácido não foi alterado $(\mathrm{P}>0,05)$ nem pelas formas de processamento da cana-de-açúcar nem pelos tempos de armazenamento. Este fato é de grande importância, pois comprova que a hidrólise da fração fibrosa já ocorreu após as primeiras 12 horas e não foi prejudicada nos tempos subsequentes.

A maior ou menor ação da cal virgem ou hidratada sobre a digestibilidade in vitro, principalmente da fibra em detergente neutro e da fibra em detergente ácido, depende de vários fatores, como a concentração de óxido de cálcio total, tamanho da partícula, quantidade utilizada na hidrólise, forma de aplicação, homogeneização da mistura (solução ou em pó), tempo de hidrólise, maturação e variedade da cana-de-açúcar, entre outros.

Tabela 2 - Digestibilidade in vitro da matéria seca, fibra em detergente neutro e fibra em detergente ácido da cana-de-açúcar hidrolisada com cal virgem ou cal hidratada

\begin{tabular}{|c|c|c|c|c|c|c|}
\hline \multirow[t]{2}{*}{ Item } & \multicolumn{3}{|c|}{ Forma de processamento } & \multicolumn{3}{|c|}{ Tempo de armazenamento } \\
\hline & In natura & $\begin{array}{c}\text { Hidrólise } \\
\text { com cal } \\
\text { virgem }\end{array}$ & $\begin{array}{l}\text { Hidrólise } \\
\text { com cal } \\
\text { hidratada }\end{array}$ & 12 horas & 36 horas & 60 horas \\
\hline Matéria seca & $58,28 b$ & $60,57 a$ & $61,27 a$ & 60,80 & 59,71 & 59,60 \\
\hline Fibra em detergente ácido & $37,35 b$ & $38,84 a$ & 32,26 & 38,40 & 38,47 & 38,65 \\
\hline Fibra em detegente neutro & 32,18 & $38,83 a$ & 32,21 & 32,14 & 32,34 & 32,18 \\
\hline
\end{tabular}

Médias seguidas de mesma letra na coluna não diferem entre si pelo teste Tukey.

\section{Conclusões}

A hidrólise com 0,5\% de cal virgem ou cal hidratada mantém o valor nutricional da cana-de-açúcar, permitindo que a cana seja utilizada depois de até 60 horas de armazenamento. Tanto a cal virgem como a cal hidratada são eficientes e podem ser utilizadas na hidrólise da cana-deaçúcar, portanto a escolha depende apenas do preço e da disponibilidade na região.

\section{Referências}

AMARAL, R.C.; PIRES, A.V.; SUSIN, I. et al. Cana-de-açúcar in natura ou ensilada com e sem aditivos químicos: estabilidade aeróbia dos volumosos e das rações. Revista Brasileira de Zootecnia, v.38, n.10, p.1857-1864, 2009.

BOIN, C.; MATTOS, W.R.S.; D’ARCE, R.D. Cana-de-açúcar e seus subprodutos na alimentação de ruminantes. In: PARANHOS, S.B. (Coord.) Cana-de-açúcar: cultivo e utilização. Campinas: Ed. Fundação Cargill, 1987. p.805-850.

DOMINGUES, F.N.; OLIVEIRA, M.D.S.; MOTA, D.A. et al. Parâmetros bromatológicos da cana-de-açúcar tratada com doses 
crescentes de cal virgem $(\mathrm{CaO})$ microprocessada em diferentes tempos de exposição ao ar. In: REUNIÃO ANUAL DA SOCIEDADE BRASILEIRA DE ZOOTECNIA, 44., 2007, Jaboticabal. Anais... Jaboticabal: Sociedade Brasileira de Zootecnia, 2007. (CD-ROM).

HOLDEN, L.A. Comparison of methods of in vitro matter digestibility for ten feeds. Journal Dairy Science, v.82, n.8, p.1791-1794, 1999.

JACKSON, M.G. Review article: the alkali treatment of straws. Animal Feed Science and Technology, v.2, n.2, p.105-130, 1977.

KLOPFENSTEIN, T. Increasing the nutritive value of crop residues by chemical treatments. In: HUBER, J.T. (Ed.) Upgrading residues and products for animals. Boca Raton: CRC Press, 1980. p.40-60.

MORAES, K.A.K.; VALADARES FILHO, S.C.; MORAES, E.H.B.K. et al. Parâmetros nutricionais de novilhas de corte alimentadas com cana-de-açúcar tratada com óxido de cálcio e diferentes níveis de concentrado. Revista Brasileira de Zootecnia, v.37, n.7, p.1301-1310, 2008.
OLIVEIRA, M.D.S. Cana-de-açúcar na alimentação de bovinos. 1.ed. Jaboticabal: FUNEP, 1999. 128p.

OLIVEIRA, M.D.S.; ANDRADE, A.T.; BARBOSA, J.C. et al. Digestibilidade da cana-de-açúcar hidrolisada ,in natura e ensilada para bovinos. Ciência Animal Brasileira, v.8, n.1, p.41-50, 2007.

OLIVEIRA, M.D.S.; BARBOSA, J.C.; MOTA, D.M. et al. Efeito da hidrólise com cal virgem sobre a composição bromatológica da cana-de-açúcar. Veterinária Noticias, v.14, n.1, p.19-27, 2008a.

OLIVEIRA, M.D.S.; SANTOS, J.; DOMINGUES, F.N. et al. Avaliação da cal hidratada como agente hidrolisante de canade-açúcar. Veterinária Noticias, v.14, n.1, p.9-17, 2008b.

ROBERTSON, J.B.; VAN SOEST, P.J. The detergent system of analysis and its application to human foods. In: __ The analysis of dietary fiber in food. New York: 1981. p.123-158.

SILVA, D.J.; QUEIROZ, C.A. Análise de alimentos (Métodos químicos e biológicos). 2.ed. Viçosa, MG: Imprensa Universitária. 2002. 165p.

VAN SOEST, P.J. Nutritional ecology of the ruminant. 2.ed. Ithaca: Cornell University Press; Comstock Publish, 1994. 476p. 